Fatt Scott (Orcid ID: 0000-0002-3796-7907)

Hay Phillipa (Orcid ID: 0000-0003-0296-6856)

Trompeter Nora (Orcid ID: 0000-0001-5800-8679)

Title:Seeing yourself clearly: Self-identification of a body image problem in adolescents with an eating disorder

Running title: Self-identification for eating disorders

Authors: Scott J. Fatt ${ }^{1,2}$ (BPsychHons), Jonathan Mond ${ }^{3,7}(\mathrm{PhD})$, Kay Bussey ${ }^{1}(\mathrm{PhD})$, Scott Griffiths $^{4}(\mathrm{PhD})$, Stuart B. Murray ${ }^{5}(\mathrm{PhD})$, Alexandra Lonergan ${ }^{1}$ (BPsychHons), Phillipa Hay ${ }^{6}$ (MD), Kathleen Pike ${ }^{2}(\mathrm{PhD})$, Nora Trompeter ${ }^{1}$ (BPsychHons), \& Deborah Mitchison ${ }^{1,7}(\mathrm{PhD})$

${ }^{1}$ Centre for Emotional Health, Department of Psychology, Macquarie University, Sydney, Australia

${ }^{2}$ Department of Psychiatry, Columbia University, New York, NY, United States of America

${ }^{3}$ Centre for Rural Health, University of Tasmania, Launceston, Australia

${ }^{4}$ Melbourne School of Psychological Sciences, University of Melbourne, Melbourne, Australia

${ }^{5}$ Department of Psychiatry, University of California San Francisco, San Francisco, CA, United States of America

${ }^{6}$ Translational Health Research Institute, School of Medicine, Western Sydney University, Sydney, Australia

${ }^{7}$ School of Medicine, Western Sydney University, Sydney, Australia

Corrresponding Author

Scott J. Fatt

Macquarie University Center for Emotional Health Ringgold standard institution

Balaclava Road, Sydney, New South Wales 2109

Australia

This is the author manuscript accepted for publication and has undergone full peer review but has not been through the copyediting, typesetting, pagination and proofreading process, which may lead to differences between this version and the Version of Record. Please cite this article as doi: 10.1111/eip.12987

This article is protected by copyright. All rights reserved. 


\begin{abstract}
Aim: Many adolescents who meet diagnostic criteria for an eating disorder do not self-identify as having a problem and may consequentlybe less likely to seek help. Extant research investigating self-identification has been limited to specific populations (i.e. girls meeting criteria for bulimic-type eating disorders). This study investigated how self-identification varied across sex, eating disorder diagnoses, and the presence of extreme eating behaviours, and how self-identification was related to help-seeking in adolescents.
\end{abstract}

Methods: Participants included 1002 Australian school students (75.5\% female, $M_{\text {age }}=15.14$ years, $S D=1.40$ ) who met DSM-5 diagnostic criteria for an eating disorder. An online survey assessed self-identification of having a body image problem, as well as sex, eating disorder diagnosis, extreme eating behaviours, help-seeking for a body image problem, and other potential correlates of self-identification (demographics, psychological distress, social function, weight and shape concerns).

Results:Approximately2 in 3adolescents with an eating disorder self-identified as having a body image problem. Girls who met criteria for a major eating disorder diagnosis, and those engaging in extreme eating behaviours, were more likely to self-identify.When adjusting for covariates, only sex remained significantly associated with self-identification. Adolescents who selfidentified were 2.71 times more likely to seek help for a body image problem, adjusting for covariates. 
Conclusions:Public health strategies ought to promote awareness regarding the different ways that body image problems might manifest among both girls and boys, as well as the potential gravity of such problems. Awareness amongst parents, teachers, and primary care providers should also be considered.

Key words:feeding and eating disorder, adolescent, identification, body image, early intervention 
The substantialpublic health burden of eating disorders (Whiteford et al., 2013) is partlydue to low rates of help-seeking(Fatt et al., 2019; Hart, Granillo, Jorm, \& Paxton, 2011). In particular, help-seeking is uncommon among adolescents, with weight and eating disorderrelated treatment received by only $27.5 \%, 21.5 \%, 11.4 \%$, and $3.4 \%$ of those meeting criteria for anorexia nervosa (AN), bulimia nervosa (BN), binge eating disorder (BED), and sub-threshold BED (sBED), respectively (Swanson, Crow, Le Grange, Swendsen, \& Merikangas, 2011). However, adolescence is a critical time for the development of disordered eating behaviours (Fairweather-Schmidt \& Wade, 2015; Treasure \& Russell, 2011).Body image concerns are a hallmark feature of eating disorders(Fairburn, Cooper, \& Shafran, 2003), and thus, help-seeking for body image concerns is an important proxy of help-seeking for eating disorders.

\section{Help-seeking and Self-identification}

Many factors are likely to influence whether and what type of treatment is received by people with eating disorders. These include, among other things, the nature of the symptoms and their impact on quality of life, beliefs about the likely helpfulness of treatment, perceived stigma associated with disclosure of specific symptoms, and awareness and understanding of how to access treatments deemed to be helpful(Bullivant, Rhydderch, Griffiths, Mitchison, \& Mond, in press; Mond, Slewa-Younan, \& Johnson, in press). These and other factors influence perceived need for treatment and, in turn, help-seeking behaviour. One other factor that has received attention in recent years, in both the general mental health and eating disorders literatures, is whether sufferers believe that they do in fact have a mental health problem, that is, their "self- 
identification” (or, in some studies, “self-recognition”) of such a problem(Regeer, Kupka, Ten Have, Vollebergh, \& Nolen, 2015; Schomerus et al., 2019).

It is reasonable to suggest that, among individuals with eating disorders, the failure to identify an eating disorder or related condition is conducive to low perceived need for treatment of an eating disorder and, in turn, low or inappropriate help-seeking. Several studies have identified poor self-identification as a barrier forhelp-seeking for an eating disorder(GratwickSarll, Mond, \& Hay, 2013; Gratwick - Sarll, Bentley, Harrison, \& Mond, 2016; Grillot \& Keel, 2018; Mond, Hay, Rodgers, \& Owen, 2006).In one study, female secondary school students with bulimic symptoms were presented with a vignette of a fictional girl displaying symptoms of BN, and were asked if they believed they had a problem such as the one described(Gratwick - Sarll et al., 2016).Self-identification was low (42.3\%), and help-seeking (while still low) was more likely for those who self-identified (24.1\% vs $8.9 \%$ ). Thus, understanding the occurrence and correlates of self-identification may help to inform early intervention programs for adolescents with eating disorders(Mond, 2014, 2016)

\section{Self-identification}

Certain disordered eating behaviours have been investigated as correlates of selfidentification. Purging for weight control purposes is positively associated with selfidentification in both adults and adolescents with bulimic-type syndromes (Gratwick - Sarll et al., 2016; Mond et al., 2006). However, other behavioural symptoms (e.g. binge eating, non-purging) 
have not yet been investigated. Further, research has been limited to bulimic-type syndromes rather than the full spectrum of eating disorder diagnoses. Unexamined diagnosesinclude the “other specified” and "unspecified” feeding and eating disorders (OSFED; UFED), which are significantly impairing and more prevalentthan full syndrome eating disorders (Hammerle, Huss, Ernst, \& Bürger, 2016), but associated with lower help-seeking(Fatt et al., 2019; Turner, BryantWaugh, \& Peveler, 2010).

Sex may also be a relevant correlate of self-identification. To date,gender differences for self-identification have not been examined in adolescents, despite growing awareness of the prevalence and impact of eating disorders in males(Hay et al., 2017; Mitchison et al., 2019; Striegel - Moore et al., 2009).Self-identification is poorer in young males compared to young females for mental health problems generally(Cotton, Wright, Harris, Jorm, \& McGorry, 2006), and help-seeking for general health problems is lower among menwith eating disorders(Thapliyal, Mitchison, Miller, et al., 2018). Therefore, it is likely that eating disorders are under-recognised by boys compared togirls.

In summary,self-identification has been linked with help-seeking in females who meet criteria for a bulimic-type eating disorder; however, this has not been investigated in males or for other eating disorder diagnoses and behaviours.This study investigated how self-identification of having an eating disorder differed as a function of sex, eating disorder diagnosis, and disordered eating behaviours (bingeeating, purging, other extreme non-purging behaviours) in a populationbased sample of adolescents with full-syndrome and residual (OSFED/UFED) eating disorders. 
Other additional correlates,for which there is evidence of a relationship with help-seeking for an eating disorder,were also examined as covariates:psychological distress and impairment in quality of life(Mond et al., 2009),body mass index(BMI; Grillot \& Keel, 2018; Thapliyal, Mitchison, Mond, \& Hay, 2018), weight and shape concerns(Thapliyal, Mitchison, Miller, et al., 2018), and school grade (which is likely correlated with mental health literacy).It was hypothesised that self-identification would be higher for girls, those with a major eating disorder (AN, BN, BED), and those who engage in binge eating, purging, and non-purging weight control behaviours; and that these relationships would remain significant adjusting for psychological distress, quality of life, BMI, age, and weight and shape concerns. Further, it was hypothesised that adolescents with eating disorders who self-identified would be more likely to seek help, adjusting for the above covariates.

\section{Method}

\section{Participants and Procedure}

Data included the first wave of the EveryBODY study, a longitudinal investigation of Australian adolescents' body image concerns and disordered eating behaviours, which has been described previously (Trompeter et al., 2018).In brief, data were collected fromstudents at13 secondary schools, representative of the Sydney/Newcastle and Hunter regions of New South Wales for socio-educational advantage. 
Ethics approval for the study was received from the University ethics committee, the Catholic Education Office, and the New South Wales Department of Education. Consentingstudentswere given an online survey to complete during class, including measures ofeating disorder pathology, sociodemographic information (school grade, sex, height and weight), self-identification, help-seeking, weight and shape concerns, psychological distress, and quality of life impairment.

The average rate of participation across schools was 70\%, resulting in 5191 responses. Of these, 39 were excluded due to excessive missing data (more than 90\% missing), 79due to nonserious responses, and one due to withdrawn consent, leaving a total of 5072 students (52.7\% female). Final analyses were conducted on the 1002 adolescents (75.5\% girls, mean age $=15.14$, $S D=1.40$ )who met the Diagnostic and Statistical Manual of Mental Disorders, fifth edition(DSM-5)criteria for a major eating disorder, OSFED, or UFED. This approximation of 1 in 5 participants meeting criteria for any eating disorder is in line with other adolescent prevalence studies that take into account the full spectrum of clinical and subclinical eating disorders(Hammerle et al., 2016; Micali et al., 2015).

\section{Measures}

Eating disorder diagnosis and behaviours.As described in fullin a previous study on the prevalence of eating disorders using the EveryBODY data(Mitchison et al., 2019), a selfreport, online questionnaireincluding the Eating Disorder Examination Questionnaire (EDE-Q; Fairburn \& Beglin, 2008)was used to assessweight/shape concerns, and the presence and 
frequency of disordered eating behaviours over the past four weeks, including: purging behaviours (self-induced vomiting or laxative misuse to control weight or shape), non-purging weight control behaviours (extreme exercise or fasting), and binge eating (eating large amounts of food in conjunction with a perceived loss of control).This questionnaire was used to determine eating disorder diagnoses according to the DSM-5 criteria. The operationalisationof these diagnoses isavailable in the supplementary file.The eating disorder diagnoses assessed include the three major eating disorders (AN, BN, BED), the five OSFED syndromes (atypicial anorexia nervosa, AAN; subthreshold bulimia nervosa, SBN; subthreshold binge eating disorder, SBED; purging disorder, PD; night eating syndrome, NES), and UFED.

Self-identification with a body image problem. Self-identification of having a body image problem was measured with two questions: "Do you think you have ever had a problem with body image?” and a follow-up question of "Do you still have this problem now?”. Participants responded either “yes” or "no”, and self-identification of having a body image problem was indicated by answering "yes" to both questions. Given that many adolescents may fail to recognise their experience as an eating disorder, a“body image problem” was chosen because it captures a central transdiagnostic tenet of eating disorders(Fairburn et al., 2003), whilst remaining comprehensible for an adolescent sample.

Help-seeking for a body image problem.Help-seeking wasindicated by answering “yes" to the question "Have you ever seen a health professional about a body image problem?". Similar to self-identification, the wording used in this question was intended to provide a proxy 
indication of help-seeking for an eating disorder that would be appropriate for an adolescent sample.

Body image disturbance.Not all DSM-5 eating disorder diagnoses include a body image criterion; therefore, a composite average of theWeight Concerns and Shape Concerns subscalesfrom the Eating Disorder Examination Questionnaire(EDE-Q; Fairburn \& Beglin, 2008) was used to control for body image disturbance in multivariate analyses.The combination of these two subscales has previously produced adequate internal consistency in Australian adolescent boys and girls previously(Mond et al., 2014), and in the present study (Cronbach’s $\alpha$ $=.94)$.

Clinical impact.Psychological distress and quality of life were measured through the Kessler Psychological Distress Scale (K10; Kessler et al., 2002) and the social functioning (3 items) subscale of the Pediatric Quality of Life Scale SF15 (PedsQL SF15; Varni, Burwinkle, Seid, \& Skarr, 2003), respectively. Both of these scales have been used previously in adolescent samples (Gall et al., 2016; Varni et al., 2003). Adequate internal consistency was evident in the present study (Cronbach’s $\alpha=.92, .84$, respectively).

\section{Data Analyses}

Analyses were conducted using SPSS version 24.Missing data were handled using pairwise deletion. Analyses used data weighted according to the population distribution of gender in the 2016 Australian Census. Each boy was worth 1.08 participants, and each girl worth 
0.93. As there were more girls than boys in the current sample, the weighted sample size was 968 (rounded).To examine the bivariate associations between self-identification with eating disorder diagnosis, sex, and disordered eating behaviours (binge eating, purging, other extreme nonpurging behaviours),chi-square analyses were used, and effect sizes determined with Cramer's V. A value of Cramer's V between 0.07 and 0.21 is considered small, between 0.21 and 0.35 is considered medium, and larger than 0.35 is considered a large effect (Sun, Pan, \& Wang, 2010).Binarylogistic regression analysis was then used to assess the relationship between selfidentification(outcome variable) and sex, eating disorder diagnosis, and disordered eating behaviours (predictor variables) adjustingforgrade, BMI percentile, psychological distress,social function, and weight and shape concerns. A second binary logistic regression analysis was used to assess the relationship between self-identification (predictor variable) and help-seeking (outcome variable),adjustingfor these other variables.

\section{Results}

Approximately two-thirds (66.1\%) of adolescents self-identified as having a current body image problem. The characteristics of adolescents with eating disorders who did and did not selfidentify having a body image problem are presented in Table 1.Adolescents reporting purging, binge eating, or non-purging eating behaviours, were significantly more likely to self-identify as having a current body image problem. Further, self-identification was associated with higher BMI, higher psychological distress, lower social function, and greater weight and shape concerns.

| Insert Table 1 here | 
Table 2 shows how the proportion of participants who self-identified as having a current problem with body image varied by eating disorder diagnosis and sex. Overall, girls were 3.24 (95\% confidence interval $[C I]=2.42-4.35)$ times more likely to self-identifythan boys, $\chi^{2}(1, N$ $=968)=64.19, p<.001$, Cramer's $V=.26$. Those who met criteria for OSFED were less likely to self-identifythan for either UFED or a major eating disorder, and this was true for both boys, $\chi^{2}$ $(2,263)=30.24, p<.001$, Cramer's $V=.34$, and girls, $\chi^{2}(2, N=702)=20.19, p<.001$, Cramer's $V=.17$. Self-identification was not significantly different between adolescents with UFED or a major eating disorder $(p>.05)$.

| Insert Table 2 here |

\section{Multivariate associations with self-identification}

Binary logistic regression analyses were conducted to assess the relationship between sex, eating disorder diagnosis, and disordered eating behaviours (binge eating, purging, non-purging), and self-identification. Without covariates, the overall model was significant, $\chi^{2}(6, N=928)=$ 134.37, $p<.001)$.When adjusting for grade, BMI percentile, psychological distress, social functioning, and weight and shape concerns (Table 3), the overall model remained significant, $\chi^{2}$ $(12, N=928)=293.68, p<.001)$. Girls were 1.57 times more likely to self-identify than boys, but the effects of eating disorder diagnosis, and disordered eating behaviours were no longer significant.

\section{| Insert Table 3 here |}




\section{Self-identification and help-seeking}

Help-seeking for a body image problem was reported by 101 (10.1\%) of the adolescents with an eating disorder. Binary logistic regression analyses were conducted to assess the relationship between self-identification and help seeking. Without covariates, the overall model was significant, $\chi^{2}(1, N=1002)=29.71, p<.001$. Those who self-identified as having a current body image problem were 4.53 times (13.4\% versus 3.0\%) more likely to seek help than those who did not self-identify, Wald $\chi^{2}(1, N=1002)=21.35, p<.001$. When adjusting for the other variables (Table 4), the overall model remained significant, $\chi^{2}(13, N=928)=44.62, p<.001$. Those who self-identified with a current body image problemwere 2.71 times more likely to seek help.

| Insert Table 4 here |

\section{Post -hoc analyses}

Since the item assessing self-identification referred to a "body image problem", and since not all ED diagnoses included a specific criterion for elevated weight/shape concerns, we investigated self-identification in those who did not meet criteria for an eating disorder, finding that $15.1 \%$ self-identified as having a body image problem. Pearson chi-square analyses indicated that this differed significantly from the $66.1 \%$ of adolescents who did meet criteria for an eating disorder, $\chi 2(1,4127)=980.772, \mathrm{p}<.001$, Cramer's $\mathrm{V}=.49$, indicating a large effect size.Further,the analyses were repeated including only those participants who met criteria for an 
eating disorder which does specify a body image disturbance component within the diagnostic criteria (i.e., those with diagnoses of AN, AAN, BN, SBN, or PD). There were no differences in the pattern of results of the primary outcomes of the study, with differences only in covariates forthe multivariable analysis of variables associated with self-identification: grade was no longer statistically significant $(p=.27$ ) while BMI percentile was of borderline significance ( $p=0.06$ ) (full details available from the first author upon request).

\section{Discussion}

The present study investigated the prevalenceof self-identification of having a body image problem in adolescents with an eating disorder, and whether this was associated with sex,eating disorder diagnosis, disordered eating behaviours, and help-seeking.Overall, approximately twoout ofthree adolescents self-identified.Those with an OSFED syndrome, those not engaging in binge eating, purging, or other extreme non-purging behaviours, and boys were less likely to self-identify. However, whenadjusting for each of the other variables, only sex remained significant. Those who self-identified were 2.71 times more likely to seek help for a body image problem, adjusting for the other covariates.

\section{Findings and implications}

Thisprovides the first prevalence rates of self-identification in adolescents with an eating disorder, including males and the DSM-5 diagnoses. Overall, the prevalence of self-identification of having a body image problem in this study (66.0\%) was much higher than the $18.2 \%$ of adults 
who self-identified as having an eating disorder problem (Grillot \& Keel, 2018). Looking at girls who met criteria for BN or sBN, self-identification (210 out of 288; 72.9\%)was higher in the current study than previous findings (42\%; Gratwick - Sarll et al., 2016). This might indicate that adolescents recognise having a "body image problem" more readily than recognition of having an eating disorder (Gratwick - Sarll et al., 2016; Grillot \& Keel, 2018; Mond et al., 2006). Alternatively, body image problems are highly endorsed amongst Australian adolescents(Mission Australia, 2018), and adolescents in this study may have agreed to having a body image problem without fully appreciating the seriousness of their disorder.

Self-identification was less likely for boys (45.8\%)than girls (73.6\%),even when adjusting for the other variables. This is inconsistent withGrillot and Keel (2018)'s findingthat self-identification did not differ between adult males and females. However, self-identification of mental health problems is generally poorer in adolescent boys compared with girls (Cotton et al., 2006).

Those who met criteria for OSFED (55.5\%) were less likely to identify than UFED (82.8\%) or a major eating disorder (78.1\%),potentiallyreflecting the poorer knowledge about “other specified’ eating disorders in the community (Mond \& Arrighi, 2011).Similarly, selfidentification was positively associated with the presence of binge-eating, purging, and other extreme non-purging behaviours, consistent with previous research (Gratwick - Sarll et al., 2016; Mond et al., 2006). However, none of these differences remained significant when adjusting for the other variables. Thus, while lower self-identification is evident among those 
with subthreshold eating disorders and thosewho do not engage in 'typical' disordered eating behaviours, this isovershadowed byother factors (sex, age, social functioning, BMI percentile, and weight and shape concerns).

Although a substantial proportion of adolescents did self-identify with having a body image problem, it is important to understandwhat moves people from self-identification to helpseeking. In the present study, those who self-identified for a body image problem were 2.71 times more likely to seek help. Thus, early intervention programsought to focus on improvingawareness and understanding of the susceptibility to eating disorders amongst boys, including education for the severity of various disordered eating behaviours(Mitchison, Basten, Griffiths, \& Murray, 2017; Mond et al., 2014; Mond, 2016; Murray et al., 2017).Although selfidentificationhas been found to relate to help-seeking in the current study, as in previous research, the vast majority of participants (87\%) who did self-identify still reported having never sought help for their body image problem, despite high levels of distress andsocial function impairment. Evidently, there are many factors that influence help-seeking in adolescents with an eating disorder beyond self-identification, including access to care, and fears of disclosing their problems to a parent or caregiver to facilitate treatment. Early intervention and health promotion programs designed to improve "eating disorders mentalhealth literacy" likely need to extendto parents, teachers, and primary care providers: an important focus for future research(Mond, 2016).

\section{Limitations, andfuture directions}


Some limitations should be considered when interpreting these results.First, both selfidentification and help-seekingwere assessed using the wording "body image problem". This non-technical term was chosen to improve comprehensibility in an adolescent sample. Body image disturbance is a core transdiagnostic etiological feature across eating disorder diagnoses(Fairburn et al., 2003) and is a familiar concept amongst adolescents (Mission Australia, 2018),butis not specified for all eating disorder diagnostic criteria (American Psychiatric Association, 2013).However, as a conservative approach,body image concerns were adjusted for in analysesby including weight and shape concerns as a covariate. Still, future studies could potentiallyusemore comprehensive measures of self-identification.

Additionally, the present study was limited by its cross-sectional study design. Although is itlikely that self-identification precedes help-seeking, the opposite could also be true: adolescents may see a health professional without personally recognising their problem (e.g. a caregiver may instigate help-seeking), and subsequently become more likely to self-identify. Longitudinal research is necessary to disentangle the direction of these relationships.

\section{Conclusion}

Many adolescents with an eating disorder self-identified having a body image problem. Adolescents with a major eating disorder, and those not engaging in binge eating, purging, or other extreme non-purging behaviours were more likely to self-identify, however these effects were overshadowed by other variables. Girls self-identified more often than boys, even whenadjusting for the other variables. Further, adolescents who self-identifiedwere more likely 
to seekhelp for a body image problem,adjusting for other factors. There are potential opportunities for early interventions aimed to improve self-identification, and potentially helpseeking. However, low rates of help-seeking amongst those who did self-identify highlights the relevance of an adolescent's broader context, including primary caregivers and health-care providers.

This article is protected by copyright. All rights reserved. 
Data sharing:The datasets generated during and/or analysed during the current study are not publicly available due to ethical constraints, but interested readers are encouraged to consult the corresponding author for such requests.

Acknowledgements:This work was supported by a Macquarie University Research Fellowship (DM) and a Society for Mental Health Research Project Grant (DM).

Conflicts of interest:Professor Hay receives/has received sessional fees and lecture fees from the Australian Medical Council, Therapeutic Guidelines publication, and New South Wales Institute of Psychiatry and royalties/honoraria from Hogrefe and Huber, McGraw Hill Education, and Blackwell Scientific Publications, Biomed Central and PlosMedicine and she has received research grants from the NHMRC and ARC. She is Deputy Chair of the National Eating Disorders Collaboration Steering Committee in Australia (2012-) and Member of the ICD-11 Working Group for Eating Disorders (2012-) and was Chair Clinical Practice Guidelines Project Working Group (Eating Disorders) of RANZCP (2012-2015). She has consulted for, and prepared a report under contract for Shire Pharmaceuticals in regards to Binge Eating Disorder (July 2017). All views in this paper are her own.

Dr. Griffiths is supported by a National Health and Medical Research Council Early Career Fellowship (grant number: 1121538).

Dr. Murray receives royalties from Oxford University Press and Routledge publishers. 


\section{References}

American Psychiatric Association. (2013). Diagnostic and statistical manual of mental disorders (DSM$\left.5^{\circledR}\right)$ : American Psychiatric Pub.

Bullivant, B., Rhydderch, S., Griffiths, S., Mitchison, D., \& Mond, J. M. (in press). Eating Disorders Mental Health Literacy: A Scoping Review. Journal of Mental Health.

Cotton, S. M., Wright, A., Harris, M. G., Jorm, A. F., \& McGorry, P. D. (2006). Influence of gender on mental health literacy in young Australians. Australian and New Zealand Journal of Psychiatry, 40(9), 790-796.

Fairburn, C. G., \& Beglin, S. (2008). Eating disorder examination questionnaire. Cognitive behaviour therapy and eating disorders.

Fairburn, C. G., Cooper, Z., \& Shafran, R. (2003). Cognitive behaviour therapy for eating disorders: A "transdiagnostic" theory and treatment. Behaviour research and therapy, 41(5), 509-528. doi:10.1016/S0005-7967(02)00088-8

Fairweather-Schmidt, A., \& Wade, T. D. J. P. m. (2015). Changes in genetic and environmental influences on disordered eating between early and late adolescence: a longitudinal twin study. 45(15), 3249-3258.

Fatt, S. J., Mond, J., Bussey, K., Griffiths, S., Murray, S. B., Lonergan, A., . . Mitchison, D. (2019). Helpseeking for body image problems among adolescents with eating disorders: Findings from the EveryBODY study. Eating and Weight Disorders-Studies on Anorexia, Bulimia and Obesity. doi:10.1007/s40519-019-00759-9

Gall, K., van Zutven, K., Lindstrom, J., Bentley, C., Gratwick - Sarll, K., Harrison, C., . . Mond, J. (2016). Obesity and emotional well - being in adolescents: Roles of body dissatisfaction, loss of control eating, and self - rated health. Obesity, 24(4), 837-842. doi:10.1002/oby.21428

Gratwick-Sarll, K., Mond, J., \& Hay, P. (2013). Self-recognition of eating-disordered behavior in college women: Further evidence of poor eating disorders "mental health literacy"? Eating disorders, 21(4), 310-327. doi:10.1080/10640266.2013.797321

Gratwick - Sarll, K., Bentley, C., Harrison, C., \& Mond, J. (2016). Poor self - recognition of disordered eating among girls with bulimic - type eating disorders: cause for concern? Early intervention in psychiatry, 10(4), 316-323.

Grillot, C. L., \& Keel, P. K. (2018). Barriers to seeking treatment for eating disorders: The role of self recognition in understanding gender disparities in who seeks help.

Hammerle, F., Huss, M., Ernst, V., \& Bürger, A. (2016). Thinking dimensional: prevalence of DSM-5 early adolescent full syndrome, partial and subthreshold eating disorders in a cross-sectional survey in German schools. BMJ open, 6(5), e010843. doi:10.1136/bmjopen-2015-010843

Hart, L. M., Granillo, M. T., Jorm, A. F., \& Paxton, S. J. (2011). Unmet need for treatment in the eating disorders: a systematic review of eating disorder specific treatment seeking among community cases. Clinical psychology review, 31(5), 727-735. doi:10.1016/j.cpr.2011.03.004

Hay, P., Mitchison, D., Collado, A. E. L., González-Chica, D. A., Stocks, N., \& Touyz, S. (2017). Burden and health-related quality of life of eating disorders, including Avoidant/Restrictive Food Intake 
Disorder (ARFID), in the Australian population. Journal of eating disorders, 5(1), 21. doi:10.1186/s40337-017-0149-z

Kessler, R. C., Andrews, G., Colpe, L. J., Hiripi, E., Mroczek, D. K., Normand, S.-L., . . Zaslavsky, A. M. (2002). Short screening scales to monitor population prevalences and trends in non-specific psychological distress. Psychological medicine, 32(6), 959-976. doi:10.1017/\$0033291702006074

Micali, N., Solmi, F., Horton, N. J., Crosby, R. D., Eddy, K. T., Calzo, J. P., . . Field, A. E. (2015). Adolescent eating disorders predict psychiatric, high-risk behaviors and weight outcomes in young adulthood. Journal of the American Academy of Child \& Adolescent Psychiatry, 54(8), 652-659. e651.

Mission Australia. (2018). Youth survey report.

Mitchison, D., Basten, C., Griffiths, S., \& Murray, S. B. (2017). Beneath the tip of the iceberg: Why so many people with eating disorders are not referred for treatment. Australian Family Physician, 46(7), 539.

Mitchison, D., Mond, J., Bussey, K., Griffiths, S., Trompeter, N., Lonergan, A., . . Hay, P. (2019). DSM-5 full syndrome, other specified, and unspecified eating disorders in Australian adolescents: prevalence and clinical significance. Psychological medicine, 1-10.

Mond, J., Hall, A., Bentley, C., Harrison, C., Gratwick - Sarll, K., \& Lewis, V. (2014). Eating - disordered behavior in adolescent boys: Eating disorder examination questionnaire norms. International Journal of Eating Disorders, 47(4), 335-341.

Mond, J., Hay, P., Rodgers, B., \& Owen, C. (2006). Self - recognition of disordered eating among women with bulimic - type eating disorders: A community - based study. International Journal of Eating Disorders, 39(8), 747-753.

Mond, J. M. (2014). Eating disorders "mental health literacy": An introduction. Journal of Mental Health, 23(2), 51-54. doi:10.3109/09638237.2014.889286

Mond, J. M. (2016). Optimizing prevention programs and maximizing public health impact are not the same thing. Eating disorders, 24(1), 20-28. doi:10.1080/10640266.2015.1113824

Mond, J. M., \& Arrighi, A. (2011). Gender differences in perceptions of the severity and prevalence of eating disorders. Early intervention in psychiatry, 5(1), 41-49.

Mond, J. M., Hay, P. J., Darby, A., Paxton, S. J., Quirk, F., Buttner, P., . . Rodgers, B. (2009). Women with bulimic eating disorders: when do they receive treatment for an eating problem? Journal of Consulting and Clinical Psychology, 77(5), 835. doi:10.1037/a0015336

Mond, J. M., Slewa-Younan, S., \& Johnson, E. (in press). Self-recognition of post-traumatic stress disorder symptoms and help-seeking behaviour among Iraqi refugees resettled in Australia. Transcultural Psychiatry.

Murray, S. B., Nagata, J. M., Griffiths, S., Calzo, J. P., Brown, T. A., Mitchison, D., . . Mond, J. M. (2017). The enigma of male eating disorders: A critical review and synthesis. Clinical psychology review, 57, 1-11.

Regeer, E. J., Kupka, R. W., Ten Have, M., Vollebergh, W., \& Nolen, W. A. (2015). Low self-recognition and awareness of past hypomanic and manic episodes in the general population. International journal of bipolar disorders, 3(1), 1-7. 
Schomerus, G., Stolzenburg, S., Freitag, S., Speerforck, S., Janowitz, D., Evans-Lacko, S., . . Schmidt, S.

(2019). Stigma as a barrier to recognizing personal mental illness and seeking help: a prospective study among untreated persons with mental illness. European archives of psychiatry and clinical neuroscience, 269(4), 469-479.

Striegel - Moore, R. H., Rosselli, F., Perrin, N., DeBar, L., Wilson, G. T., May, A., \& Kraemer, H. C. (2009). Gender difference in the prevalence of eating disorder symptoms. International Journal of Eating Disorders, 42(5), 471-474. doi:10.1002/eat.20625

Sun, S., Pan, W., \& Wang, L. L. (2010). A comprehensive review of effect size reporting and interpreting practices in academic journals in education and psychology. Journal of Educational Psychology, $102(4), 989$.

Swanson, S. A., Crow, S. J., Le Grange, D., Swendsen, J., \& Merikangas, K. R. (2011). Prevalence and correlates of eating disorders in adolescents: Results from the national comorbidity survey replication adolescent supplement. Archives of general psychiatry, 68(7), 714-723. doi:10.1001/archgenpsychiatry.2011.22

Thapliyal, P., Mitchison, D., Miller, C., Bowden, J., Alejandro González-Chica, D., Stocks, N., .. . Hay, P. (2018). Comparison of mental health treatment status and use of antidepressants in men and women with eating disorders. Eating disorders, 26(3), 248-262.

Thapliyal, P., Mitchison, D., Mond, J., \& Hay, P. (2018). Gender and help-seeking for an eating disorder: findings from a general population sample. Eating and Weight Disorders-Studies on Anorexia, Bulimia and Obesity, 1-6.

Treasure, J., \& Russell, G. (2011). The case for early intervention in anorexia nervosa: theoretical exploration of maintaining factors. The British Journal of Psychiatry, 199(1), 5-7. doi:10.1192/bjp.bp.110.087585

Trompeter, N., Bussey, K., Hay, P., Mond, J., Murray, S., Lonergan, A., . . Mitchison, D. (2018). Fear of Negative Evaluation and Weight/Shape Concerns among Adolescents: The Moderating Effects of Gender and Weight Status. Journal of youth and adolescence, 47(7), 1-11. doi:10.1007/s10964018-0872-z

Turner, H., Bryant-Waugh, R., \& Peveler, R. (2010). The clinical features of EDNOS: relationship to mood, health status and general functioning. 11(2), 127-130.

Varni, J. W., Burwinkle, T. M., Seid, M., \& Skarr, D. (2003). The PedsQL ${ }^{\mathrm{TM} *} 4.0$ as a pediatric population health measure: feasibility, reliability, and validity. Ambulatory pediatrics, 3(6), 329-341. doi:10.1177/1359105309103580

Whiteford, H. A., Degenhardt, L., Rehm, J., Baxter, A. J., Ferrari, A. J., Erskine, H. E., . . Johns, N. (2013). Global burden of disease attributable to mental and substance use disorders: findings from the Global Burden of Disease Study 2010. The Lancet, 382(9904), 1575-1586. doi:10.1016/S01406736(13)61611-6 
Table 1.

Psychological and demographic correlates of self-identification of having a body image problem in adolescents with an eating disorder

\begin{tabular}{|c|c|c|c|c|c|}
\hline & $\begin{array}{l}\text { Did self- } \\
\text { identify } M \\
\text { (SD) }\end{array}$ & $\begin{array}{l}\text { Did not self- } \\
\text { identify } M \\
\text { (SD) }\end{array}$ & $t(\mathrm{df})$ & $p$ & $d(95 \% \mathrm{CI})$ \\
\hline BMI percentile & $66.18(28.55)$ & $55.38(30.24)$ & $-5.46(966)$ & $<.001$ & $0.37(0.24-0.51)$ \\
\hline $\begin{array}{l}\text { Psychological } \\
\text { distress }\end{array}$ & 32.24 (10.08) & $26.29(9.88)$ & $-8.63(944)$ & $<.001$ & $0.60(0.46-0.73)$ \\
\hline Social function & $62.22(29.01)$ & 71.89 (27.39) & $4.80(894)$ & $<.001$ & $0.34(0.20-0.48)$ \\
\hline \multirow{2}{*}{$\begin{array}{l}\text { Weight and } \\
\text { shape concerns }\end{array}$} & $4.62(1.12)$ & $2.76(1.77)$ & $-19.85(966)$ & $<.001$ & $1.35(1.20-1.49)$ \\
\hline & $\begin{array}{l}\text { Did self- } \\
\text { identify, } \mathrm{n} \\
(\%)\end{array}$ & $\begin{array}{c}\text { Did not self- } \\
\text { identify, } \mathrm{n} \\
(\%)\end{array}$ & $\bar{\sigma}^{2}(\mathrm{df})$ & $p$ & Cramer's $V$ \\
\hline Age & $201(62.8)$ & 119 (37.2) & $\begin{array}{c}3.37(5, N= \\
968)\end{array}$ & .186 & .06 \\
\hline Grade 7/8 & $318(66.4)$ & $161(33.6)$ & & & \\
\hline $\begin{array}{l}\text { Grade 9/10 } \\
\text { Grade 11/12 }\end{array}$ & $120(71.0)$ & 49 (29.0) & & & \\
\hline Any binge eating & $365(70.2)$ & 155 (29.8) & $\begin{array}{c}8.49(1, N= \\
967)\end{array}$ & .004 & .09 \\
\hline No binge eating & 274 (61.3) & $173(52.7)$ & & & \\
\hline Any purging & $197(74.1)$ & 69 (25.9) & $\begin{array}{c}10.33(1, N= \\
968)\end{array}$ & .001 & .10 \\
\hline No purging & $443(63.1)$ & 259 (36.9) & & & \\
\hline $\begin{array}{l}\text { Any non-purging } \\
\text { behaviours }\end{array}$ & 515 (71.3) & 207 (28.7) & $\begin{array}{c}35.24(1, N= \\
969)\end{array}$ & $<.001$ & .19 \\
\hline $\begin{array}{l}\text { No non-purging } \\
\text { behaviours }\end{array}$ & $125(50.6)$ & $122(49.4)$ & & & \\
\hline
\end{tabular}

Note.Emboldened text indicate significance at the .05 level. Analyses were conducted, weighted based on the gender population distribution in the 2016 Australian Census. BMI = body mass index; $\mathrm{CI}=$ confidence interval.

This article is protected by copyright. All rights reserved. 
Table 2.

Self-identification of having a body image problem in adolescents with an eating disorder by sex and eating disorder diagnosis

\begin{tabular}{lcccc}
\hline & \multicolumn{2}{c}{$N($ Weighted $N)$} & \multicolumn{2}{c}{ Self-identified $n(\%)$} \\
\hline & Boys & Girls & Boys & Girls \\
\hline Any ED & $245(263)$ & $757(702)$ & $121(45.8)$ & $519(73.6)$ \\
AN & $1(1)$ & $31(29)$ & $1(100.0)$ & $19(65.5)$ \\
BN & $40(43)$ & $175(163)$ & $29(67.4)$ & $134(82.2)$ \\
BED & $4(4)$ & $43(40)$ & $3(75.0)$ & $33(82.5)$ \\
AAN & $26(28)$ & $111(104)$ & $19(67.9)$ & $84(80.8)$ \\
SBN & $36(39)$ & $113(105)$ & $17(43.6)$ & $76(72.4)$ \\
SBED & $3(3)$ & $12(12)$ & $0(0.0)$ & $5(41.7)$ \\
PD & $31(34)$ & $92(86)$ & $11(32.4)$ & $46(53.5)$ \\
NES & $82(89)$ & $48(44)$ & $22(24.7)$ & $21(47.7)$ \\
UFED & $22(23)$ & $132(122)$ & $19(82.6)$ & $101(82.8)$ \\
OSFED & $178(192)$ & $376(349)$ & $69(35.9)$ & $231(66.2)$ \\
Major eating disorder $^{\mathrm{a}}$ & $45(48)$ & $249(231)$ & $33(68.8)$ & $185(80.1)$ \\
\hline
\end{tabular}

Note. Dissimilar subscript letters indicate significant differences. AN = anorexia nervosa, BN = bulimia nervosa, $\mathrm{BED}=$ binge eating disorder, $\mathrm{AAN}=$ atypical anorexia nervosa, $\mathrm{SBN}=$ sub-threshold bulimia nervosa, SBED = sub-threshold binge eating disorder, $\mathrm{PD}=$ purging disorder, NES = night eating syndrome, UFED = unspecified feeding and eating disorder, OSFED = otherwise specified feeding and eating disorder (includes AAN, SBN, SBED, PD, NES), Major eating disorder includes AN, BN, BED.

This article is protected by copyright. All rights reserved. 
Table 3.

Multivariate analysis of variables associated with self-identification of having a body image problem

\begin{tabular}{lccc}
\hline Correlate (reference category) & $\begin{array}{c}\text { Adjusted odds ratio of self- } \\
\text { identification }(95 \% \mathrm{CI})\end{array}$ & Wald $?^{2}$ & $p$ \\
\hline Sex (boy) & $\mathbf{1 . 5 7}(\mathbf{1 . 0 4}-\mathbf{2 . 3 8 )}$ & $\mathbf{4 . 6 3}$ & $\mathbf{. 0 3 1}$ \\
UFED (Major eating disorder) & $1.17(0.63-2.16)$ & 0.25 & .615 \\
OSFED (Major eating disorder) & $0.77(0.50-1.19)$ & 1.38 & .240 \\
Binge eating & $0.96(0.65-1.42)$ & 0.04 & .834 \\
Purging behaviours & $1.420 .94-2.13)$ & 2.76 & .096 \\
Non-purging behaviours & $1.03(0.68-1.55)$ & 0.02 & .893 \\
Grade 11/12 (grade 7/8) & $\mathbf{1 . 2 2}(\mathbf{1 . 0 6}-\mathbf{3 . 2 4 )}$ & $\mathbf{4 . 7 1}$ & $\mathbf{. 0 3 0}$ \\
Grade 9/10 (grade 7/8) & $1.850 .85-1.75)$ & 1.19 & .276 \\
BMI percentile & $\mathbf{1 . 0 1}(\mathbf{1 . 0 0}-\mathbf{1 . 0 1})$ & $\mathbf{6 . 0 1}$ & $\mathbf{. 0 1 4}$ \\
Psychological distress & $1.01(0.99-1.03)$ & 0.29 & .587 \\
Social functioning & $\mathbf{0 . 9 9}(\mathbf{0 . 9 8}-\mathbf{1 . 0 0})$ & $\mathbf{6 . 7 1}$ & $\mathbf{. 0 1 0}$ \\
Weight and shape concerns & $\mathbf{1 . 9 4}(\mathbf{1 . 6 9}-\mathbf{2 . 2 3 )}$ & $\mathbf{8 5 . 8 0}$ & $<.001$ \\
\hline
\end{tabular}

Note. Emboldened text indicate significance at the .05 level. Analyses were conducted, weighted based on the gender population distribution in the 2016 Australian Census. UFED = unspecified feeding and eating disorder, OSFED = other specified feeding and eating disorder, $\mathrm{BMI}=$ body mass index, $\mathrm{CI}=$ confidence interval.

This article is protected by copyright. All rights reserved. 
Table 4.

Multivariate analysis of variables associated with help-seeking for a body image problem

\begin{tabular}{lccc}
\hline Correlate (reference category) & $\begin{array}{c}\text { Adjusted Odds ratio of help- } \\
\text { seeking (95\% CI) }\end{array}$ & Wald $\Xi^{2}$ & $p$ \\
\hline Self-identification (yes) & $\mathbf{2 . 7 1 ( 1 . 3 2 - 5 . 5 5 )}$ & $\mathbf{7 . 3 7}$ & $\mathbf{. 0 0 7}$ \\
\hline Sex (boy) & $0.91(0.49-1.67)$ & 0.10 & .752 \\
UFED (Major eating disorder) & $\mathbf{0 . 3 2}(\mathbf{0 . 1 2}-\mathbf{0 . 8 4})$ & $\mathbf{5 . 3 3}$ & $\mathbf{. 0 2 1}$ \\
OSFED (Major eating disorder) & $1.02(0.58-1.80)$ & 0.00 & .952 \\
Binge eating & $0.87(0.50-1.52)$ & 0.24 & .624 \\
Purging behaviours & $1.14(0.69-1.87)$ & 0.26 & .609 \\
Non-purging behaviours & $1.01(0.56-1.83)$ & 0.00 & .974 \\
Grade 11/12 (Grade 7/8) & $1.61(0.82-3.18)$ & 1.90 & .168 \\
Grade 9/10 (Grade 7/8) & $1.12(0.67-1.87)$ & 0.18 & .673 \\
BMI percentile & $1.00(0.99-1.01)$ & 0.00 & .968 \\
Psychological distress & $1.02(0.99-1.05)$ & 1.77 & .184 \\
Social functioning & $1.00(0.99-1.01)$ & 0.13 & .719 \\
Weight and shape concerns & $1.21(0.97-1.51)$ & 2.76 & .097 \\
\hline
\end{tabular}

Note. Emboldened text indicate significance at the .05 level. Analyses were conducted, weighted based on the gender population distribution in the 2016 Australian Census. $n=928$. UFED = unspecified feeding and eating disorder, OSFED = other specified feeding and eating disorder, $\mathrm{BMI}=$ body mass index, $\mathrm{CI}$ = confidence interval.

This article is protected by copyright. All rights reserved. 


\section{University Library}

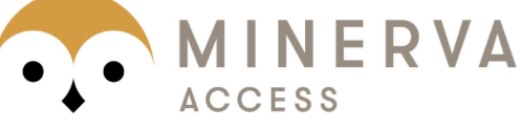

A gateway to Melbourne's research publications

Minerva Access is the Institutional Repository of The University of Melbourne

Author/s:

Fatt, SJ;Mond, J;Bussey, K;Griffiths, S;Murray, SB;Lonergan, A;Hay, P;Pike, K;Trompeter, $\mathrm{N}$;Mitchison, D

Title:

Seeing yourself clearly: Self-identification of a body image problem in adolescents with an eating disorder

Date:

2020-05-19

Citation:

Fatt, S. J., Mond, J., Bussey, K., Griffiths, S., Murray, S. B., Lonergan, A., Hay, P., Pike, K., Trompeter, N. \& Mitchison, D. (2020). Seeing yourself clearly: Self-identification of a body image problem in adolescents with an eating disorder. EARLY INTERVENTION IN PSYCHIATRY, 15 (3), pp.577-584. https://doi.org/10.1111/eip.12987.

Persistent Link:

http://hdl.handle.net/11343/275769 